\title{
OBSERVATIONS OF ACOUSTIC EMISSION IN A HYDRODYNAMIC BEARING
}

\author{
School of Engineering, Cranfield University, Bedfordshire. MK43 0AL, UK
}

S. Ali Mirhadizadeh, D. Mba

\begin{abstract}
Numerous studies have been conducted in the field of Acoustic Emission technology applied to rotating machine fault diagnosis. Principally most of the work to date has been focused on correlating Acoustic Emission (AE) activity to the defect condition on rolling element bearings with limited investigations on hydrodynamic bearings. In developing the $\mathrm{AE}$ technology for monitoring hydrodynamic bearings operated under variable speed and load conditions it is essential that a relationship between the operational variables and the generation of $\mathrm{AE}$ is established. This paper presents experimental tests aimed at understanding the influence of speed and load on generation of Acoustic Emission in a hydrodynamic bearing. It is concluded that the power losses associated which such bearings has a direct influence on the generation of AE.
\end{abstract}

Keywords: Acoustic Emission, Condition monitoring, Hydrodynamic bearing.

\section{Introduction}

Acoustic Emission (AE) is defined as the range of phenomena that results in the generation of structure-borne and fluid-borne propagating waves due to the rapid release of energy from localised sources within and/or, on the surface of a material [1]. The typical frequency content of $\mathrm{AE}$ is within the range of $100 \mathrm{kHz}$ to $1 \mathrm{MHz}$. 
The AE technology is continually developing into a complimentary technology to other condition monitoring technologies such as vibration analysis [2, 12-29 ].

In the application of AE to hydrodynamic bearings (journal bearings) Sato [3] was the first investigator that directly addressed monitoring the integrity of such bearings with AE. Typical problems that are associated with journal bearings include wear and metal wipe which is a direct consequence of the shaft making contact with the journal. Such frictional contact is a prime source of AE. Others [4 to 8] have applied the AE technology to shaftseal rubbing in large power generation turbines. Leahy et al [9] undertook the most realistic controlled verification of applicability of AE to shaft seal rubbing and AlShaikh Mubarak et al [10] attempted to apply the technology for monitoring blade rubbing. Whilst in all the cases highlighted above the measurement of AE was predominately made at the journal bearing housing, no attempt was made to understand the factors that govern the generation of $\mathrm{AE}$ within the bearing as a function of the operational variables such as load, film thickness and speed. The aim of this investigation is to ascertain the relationship between rotational speed, applied load, theoretical film thickness and AE r.m.s for hydrodynamic bearing, which hitherto has not .been explored.

\section{EXPERIMENTAL PROGRAMME}

The hydrodynamic bearing test rig employed for this study had an operational speed range of between 500 to $4000 \mathrm{rpm}$. The test bearing had a radius of $40 \mathrm{~mm}$, length of $80 \mathrm{~mm}$ and a recommended radial clearance of $0.04 \mathrm{~mm}$. The bearing was lubricated with Castrol Magna BD 68 (ISO 32) with a base oil kinematic viscosity at $40^{\circ} \mathrm{C}$ and $100^{\circ} \mathrm{C}$ of $68 \mathrm{cSt}$ and $8.8 \mathrm{cSt}$ respectively. For these tests a maximum load of $800 \mathrm{~N}$ was applied. One of the fundamental reasons for testing under very lightly loaded 
conditions was to ensure that a minimum film thickness of the test bearings was much larger than the surface roughness of the bearing ( $3 \mu \mathrm{m} \mathrm{Ra})$.

Two Physical Acoustics Pico type sensors (200 KHz to $750 \mathrm{KHz}$ frequency bandwidth) were placed directly onto the test bearing at each end, see figure 2 . The sensor output was amplified at $40 \mathrm{~dB}$. The 'PICO' type sensor was employed due to its size (5 $\mathrm{mm}$ in diameter and $5 \mathrm{~mm}$ in height) making it suitable for placement in confined areas.

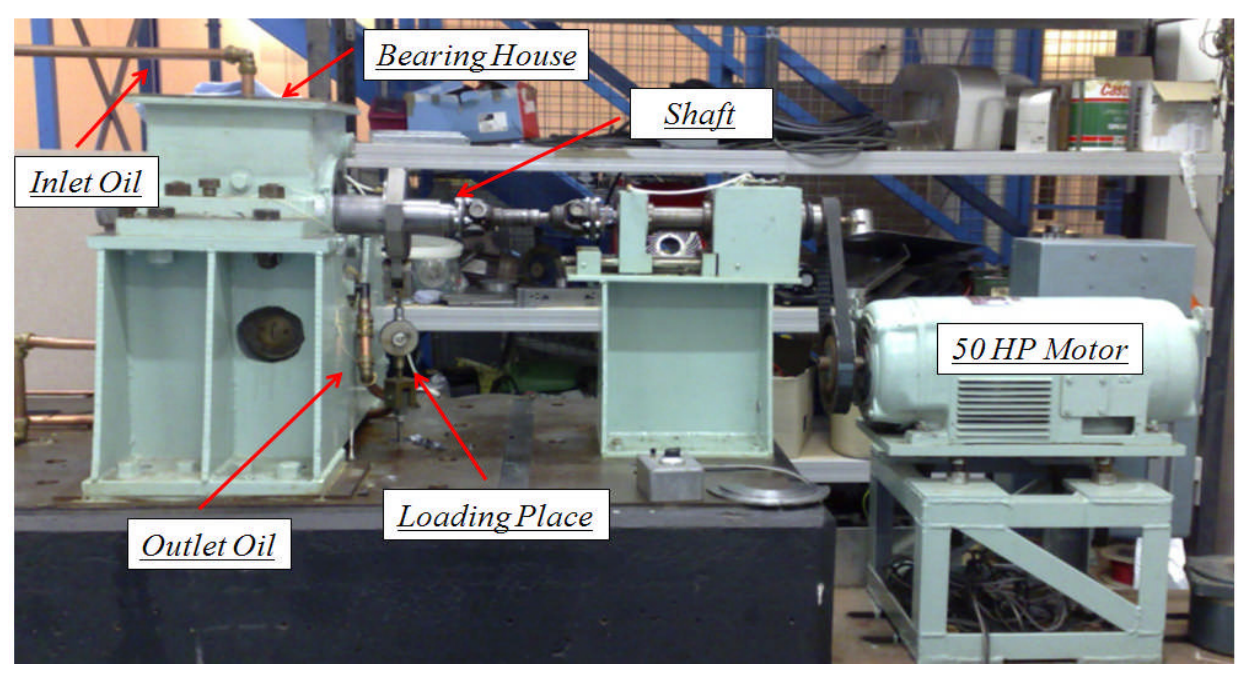

Figure 1 Test rig layout

In addition, two thermocouples used for measuring the journal temperature during the tests were welded onto the bearing race adjacent to the AE sensors. The test conditions investigated included five rotational speeds 500, 1000, 2000, 3000 and $4000 \mathrm{rpm}$ and six load conditions, 300N, 400N, 500N, 600N, 700N and 800N. Loading was accomplished by placing weights onto a load plate linked to the rotating shaft either side of the test bearing, see figure 1 . As such for a test condition of $800 \mathrm{~N}$, 
$400 \mathrm{~N}$ force was applied to each loading plate. Acoustic Emission r.m.s values were calculated in real time by the analogue-to-digital converter over a time constant of 10milli-seconds and at a sampling rate of $100 \mathrm{~Hz}$. AE waveforms were sampled at 2MHz.

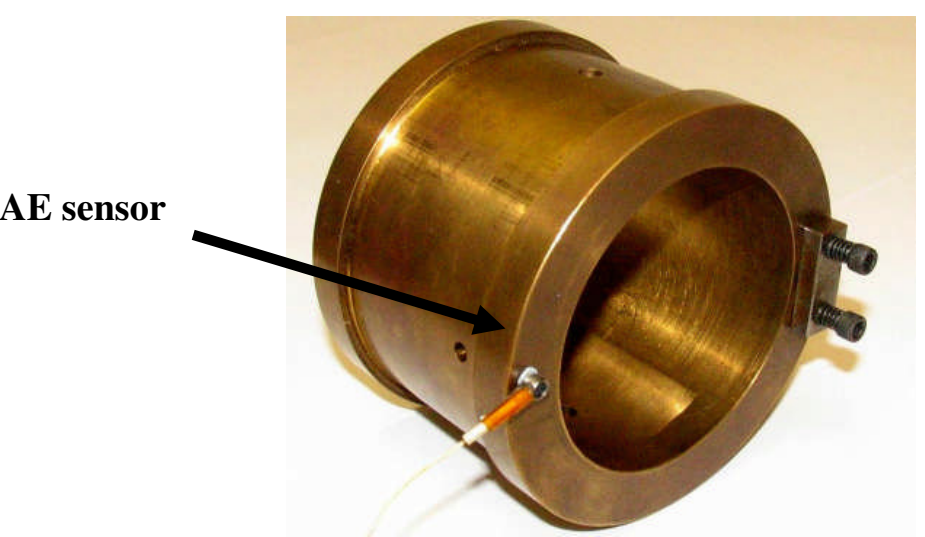

Figure 2 Location of $\mathrm{AE}$ and thermocouple sensors on test bearing

For this investigation tests involved varying the applied bearing load for fixed rotational speed whilst recording the AE r.m.s activity; each load condition was investigated under near constant temperatures. This was done in an attempt to eliminate the influence of temperature during the tests. Prior to performing the tests, the temperature of the test bearing was raised to approximately $40^{\circ} \mathrm{C}$; this was achieved by running the test-rig in excess of $1000 \mathrm{rpm}$ at $100 \mathrm{~N}$. As soon as the desired temperature was reached, the test sequence began. The test involved running the bearing at five rotational speeds and increasing the radial load, starting at $150 \mathrm{~N}$, and increasing the load in $50 \mathrm{~N}$ increments every 5-minutes to a maximum of $400 \mathrm{~N}$. The five speed conditions investigated were, 500, 1000, 2000, 3000, and $4000 \mathrm{rpm}$. The test simulations under each load and speed condition was maintained at 5-minutes as longer operation would have significantly comprised the authors attempts to 
maintain near isothermal conditions. Over 4 experimental tests programmes were undertaken where the experimental procedure described was repeated.

\section{RESULTS AND DISCUSSIONS}

The results of this test are presented in figures 3, 4 and 5. Figure 3 highlights observations of theoretical minimum film thickness (ho) and AE r.m.s measured on the bearing for a fixed speed condition. It is evident is that an increase in load resulted in a decrease in theoretical minimum film thicknesses and a corresponding increase in measured AE r.m.s values. This highlighted the sensitivity of the AE technology is discriminating such small differences in film thickness. Also It must be noted that during these test conditions, the temperature varied by a maximum of approximately $\pm 3^{\circ} \mathrm{C}$. All calculations of minimum film thickness and power losses were based on well established procedures [11].

From figure 4, it was noted that the change in load had a negligible influence on the level of AE activity for that particular speed condition, however, the change in rotational speed increased AE levels significantly even though the actual predicted change in minimum film thickness with increased speed was of the order of less than $1 \%$ for the tests conditions (see table A1 in Appendix). The corresponding increase in $\mathrm{AE}$ levels from changes in speed were in the order of over $150 \%$ on average, see table A2 in the Appendix. The authors attribute this significant change to the shearing effect of the lubricant which is a function of the rotational speed. As with hydrodynamic bearings there is no asperity contact and the corresponding increase in $\mathrm{AE}$ levels is attributed to the friction associated with the shearing of the lubricant. The values of $\mathrm{AE}$ r.m.s and minimum film thickness presented in figures 3 and 4 were 
obtained by averaging all AE r.m.s and ho values measured and calculated over the specific load condition.

Observations showed AE levels increased with power losses, see figure 5, and averaged data is given in the appendix, table A3. All calculations of power loss at every test condition are presented in figure 5. It is worth stating that due to the minimal influence of load on film thickness under these test conditions, the power losses associated with varying loads, at the same speed condition, was very similar, see figure 5. The increase in $\mathrm{AE}$ with power loss was not surprising given that increase in speed results in more power loss due to the increased friction in the shearing of the lubricant. A reduced minimum film thickness causes increased power losses and such energy losses are noted by an increase in AE r.m.s levels. A relationship between the power losses and AE r.m.s levels was determined:

$$
\mathrm{AE}(\text { r.m.s in volts })=\mathrm{A} \cdot \mathrm{W}^{3}-\mathrm{B} \cdot \mathrm{W}^{2}+\mathrm{C} \cdot \mathrm{W}-\mathrm{D}
$$

where $W=$ power loss $(K W), A=.006, B=0.005 . C=0.01$ and $D=0.01$

This equation holds based on the assumption that the load has minimal influence on the film thickness which is the case for this investigation. 


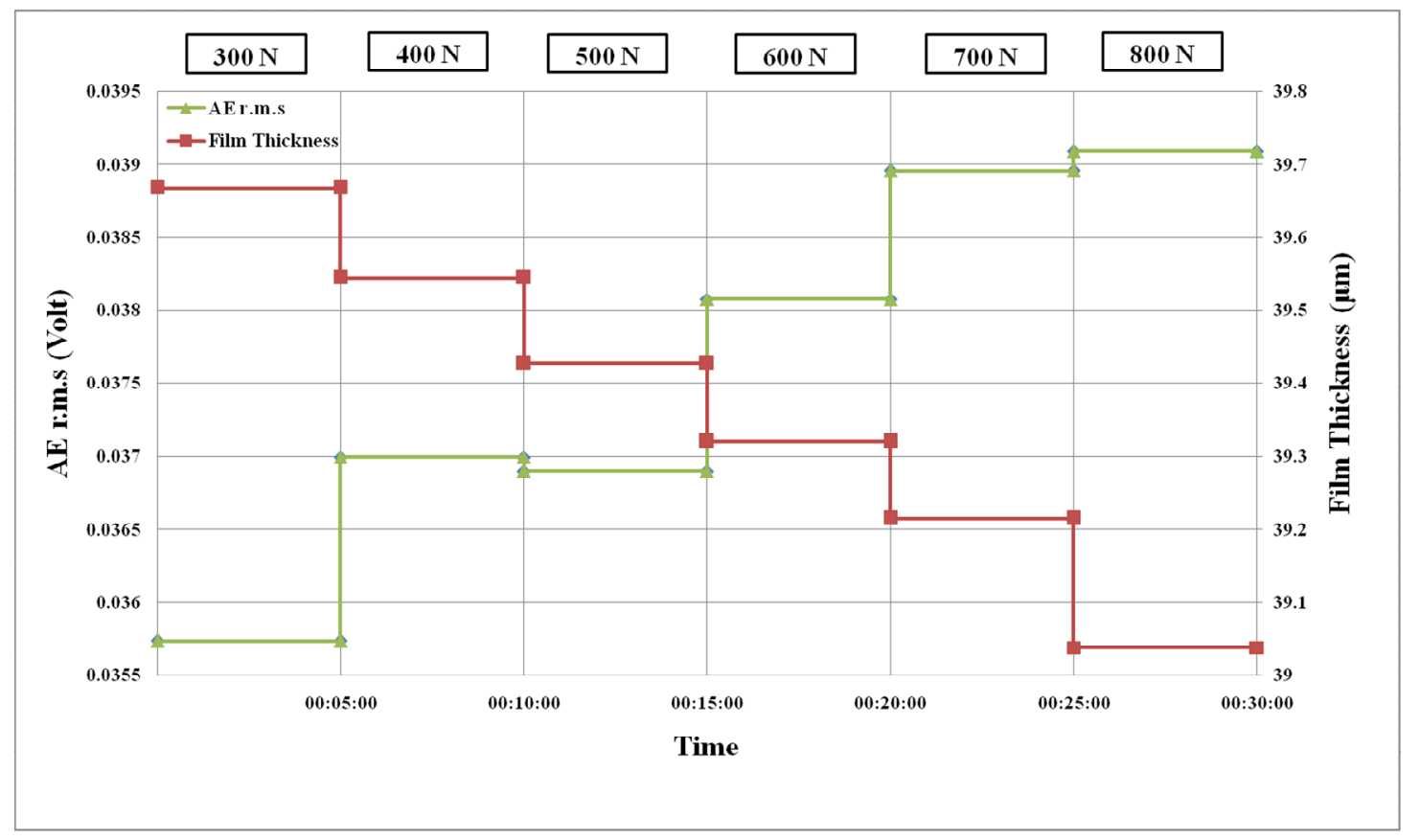

Figure 3 AE r.m.s levels for Load conditions (4000 rpm)

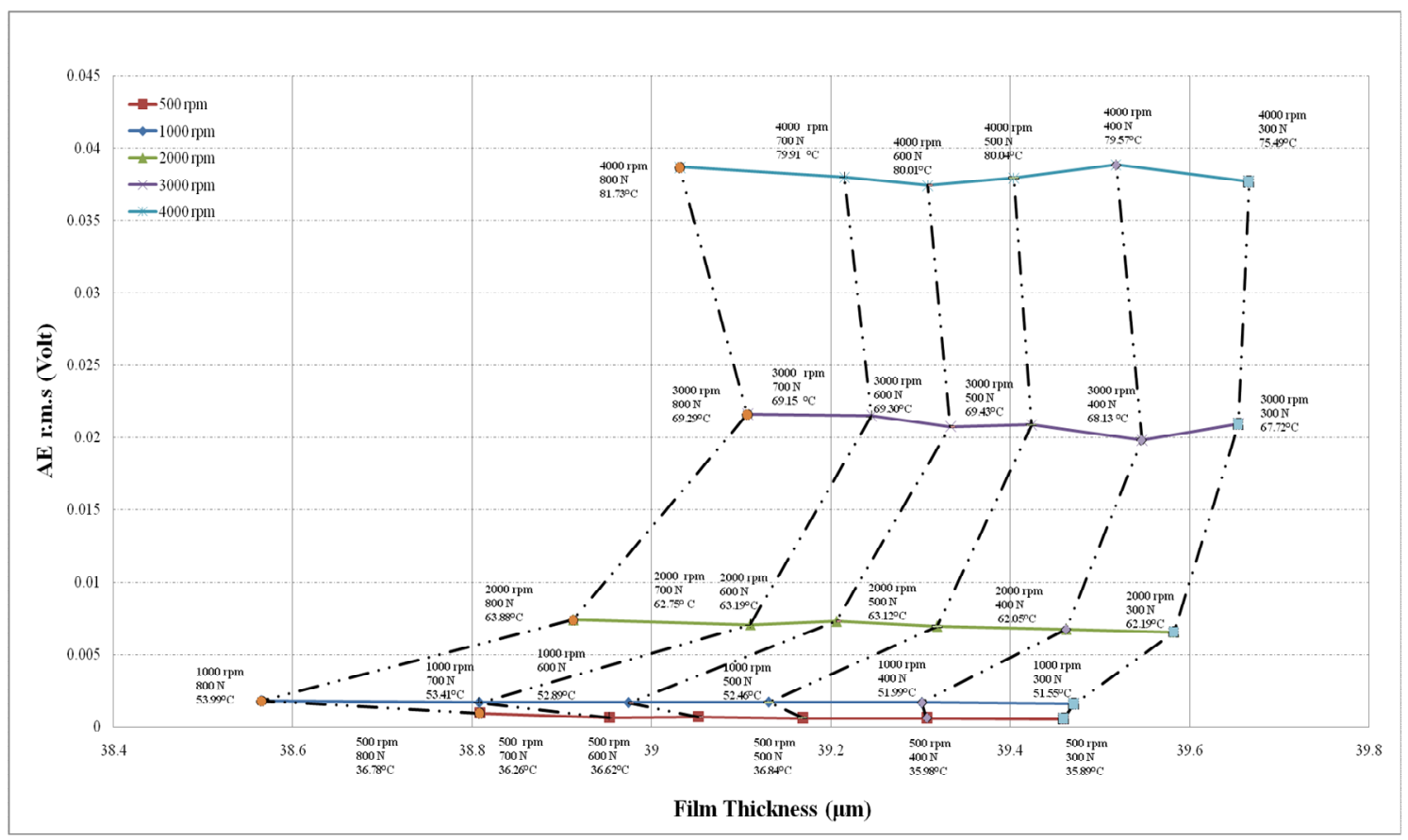

Figure 4 AE r.m.s levels for varying speed and load conditions (40dB amplification) 


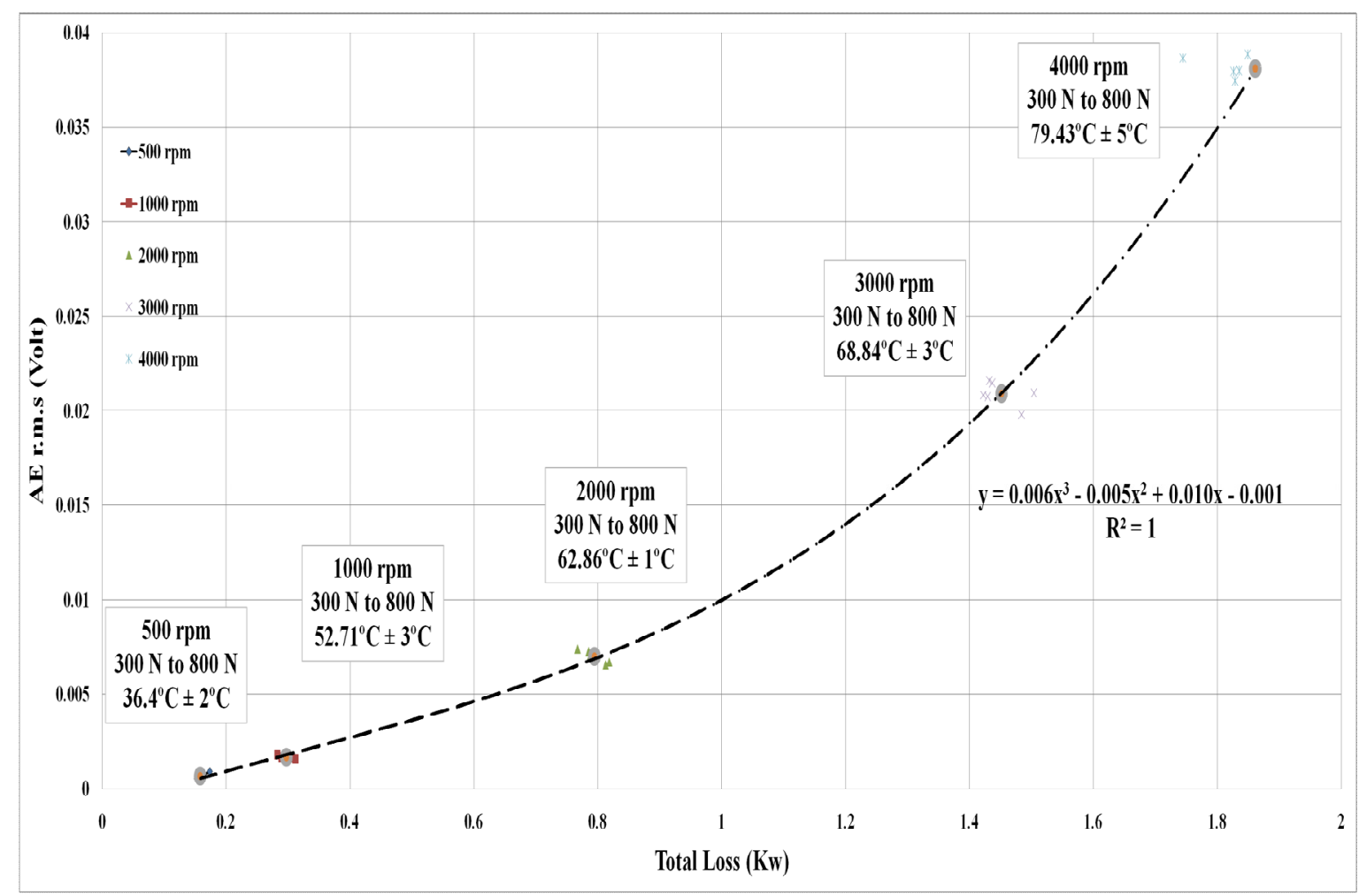

Figure 5 AE r.m.s and total power loss for varying speed and load conditions

\subsection{Rubbing Test}

A presumption made for most of the results presented is that under hydrodynamic conditions there is no asperity contact between the rotating shaft the bearing. It was thought prudent to assess the sensitivity of the AE measurements to the onset of contact between the shaft and the journal. In the rubbing tests the shaft was forced to rub against the journal. This was achieved by slowly increasing the load on the bearing at the drive end only; the loading of the bearing was changed rapidly at incremental values of $50 \mathrm{~N}$ force to a maximum load of $400 \mathrm{~N}$. Initially the test was run at $1000 \mathrm{rpm}(16.67 \mathrm{~Hz})$ with a $50 \mathrm{~N}$ load for 5 minutes, after which $50 \mathrm{~N}$ increments were made within a two minute time frame to the maximum load of $400 \mathrm{~N}$ at the drive end only. Interestingly, at $350 \mathrm{~N}$ a significant increase in $\mathrm{AE}$ levels was noted, see figure 6. In addition, $\mathrm{AE}$ waveforms were acquired at each force increment as depicted in figure 6. It was noted that associated with the rise in AE levels the $\mathrm{AE}$ 
waveform was modulated at the rotational shaft speed, see figure 6 and 7. Figure 7 highlights a few AE waveforms showing varying degrees of amplitude of the modulated waveform, which is postulated to be a function of the intensity of the rub. Such observations validate the results of others $[3,4]$ as indicative of a rubbing contact within the journal.

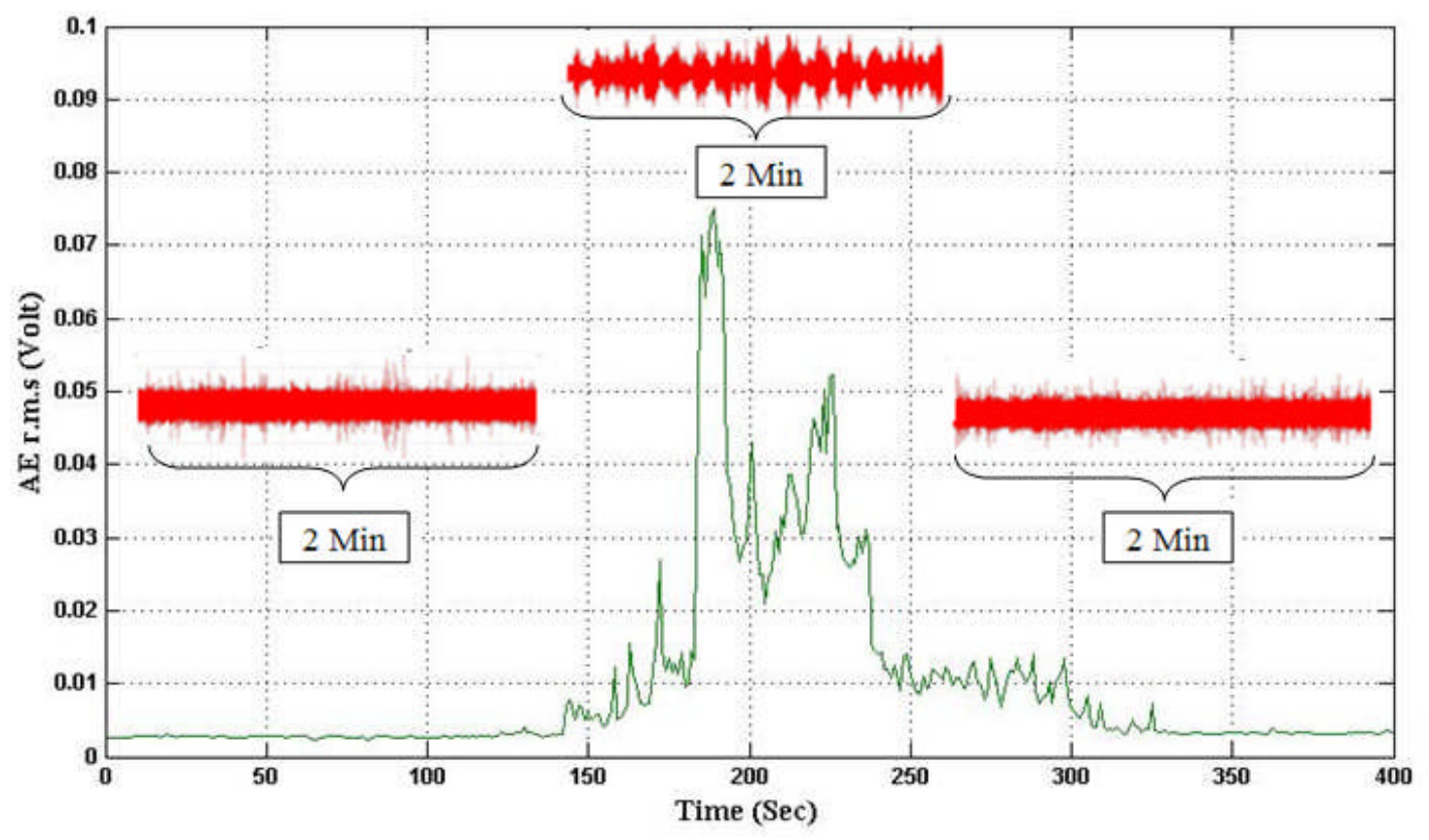

Figure 6 AE r.m.s levels and associated sample waveform during rub tests 

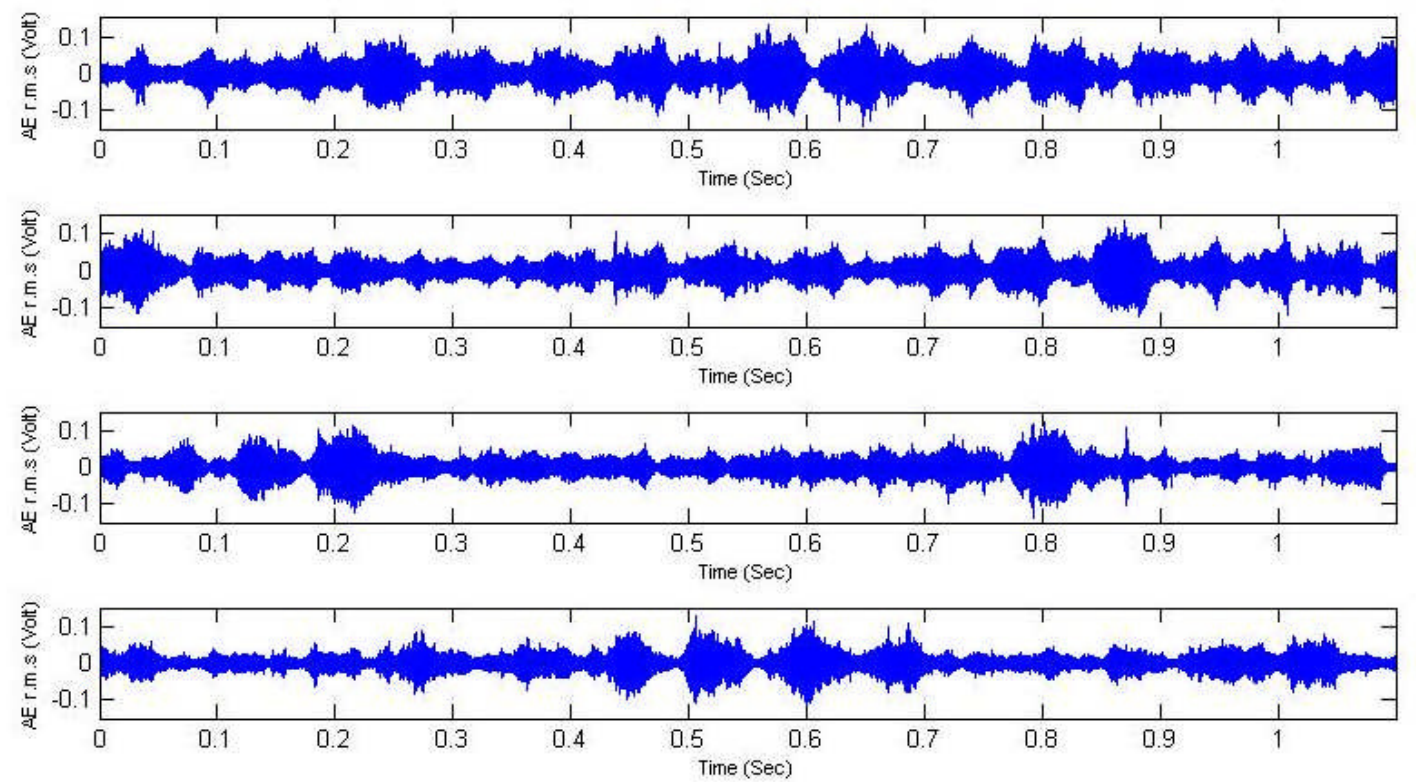

Figure 7 Modulated AE waveforms due to rubbing between 170 seconds

and 220 seconds of figure 6

\section{CONCLUSIONS}

The observations presented have confirmed that in a properly maintained hydrodynamic lubrication regime a principal source of $\mathrm{AE}$ is the friction in the shearing of the lubricant. It has been shown that an increase in running speed generates higher AE activity in comparison to an increase in bearing load. This is attributed to the powers losses as a direct result of shearing of the lubricant film. Lastly, the application of AE to detection of bearing wipe has been demonstrated and further research is needed to fully understand the influence of operational variables on AE over a much broader operating range, including oil viscosity and bearing material effects. 


\section{REFERENCES}

1. ISO 20096, Condition Monitoring and Diagnostic of Machines, Acoustic Emission - General Guidelines, 2007.

2. Mba, D. and Rao, R.B.K.N., 2006, "Development of Acoustic Emission Technology for Condition Monitoring and Diagnosis of Rotating Machines; Bearings, Pumps, Gearboxes, Engines and Rotating Structure,” The Shock and Vibration Digest, 38/1, pp 3-16.

3. Sato, I., (1990) "Rotating Machinery Diagnosis with Acoustic Emission Techniques", Electrical Engineering in Japan, Vol. 110, No. 2.

4. M. Leahy, D. Mba, P. Cooper, A. Montgomery, D. Owen, An experimental investigation into the capabilities of Acoustic Emission for the detection of shaft-to-seal rubbing in large power generation turbines, Journal of Engineering Tribology, Proc. Instn Mech. Engrs, Part J. 220(J7), 607 - 615, 2006.

5. M. Leahy, D. Mba, Detecting shaft-to-seal rubbing in power generation turbines with the Acoustic Emission technology, Journal of Vibration and Acoustics, ASME, Volume 128, Issue 6, 798-800, 2006.

6. Mba, D., Cooke, A., Roby, D., Hewitt, G., (2004) "Detection of shaft-seal rubbing in large-scale power generation turbines with Acoustic Emissions; Case study", Journal of Power and Energy - Part A, I Mech E, Vol. 218, No. 2, pp. 71-82.

7. Hall L. D., and Mba, D., Acoustic emissions diagnosis of rotor-stator rubs using the KS statistic, Mechanical Systems and Signal Processing, Volume 18, Issue 4, Pages 849-868, 2004.

8. Wang, Q. and Chu, F., Experimental determination of the rubbing location by means of acoustic emission and wavelet transform, Journal of Sound and Vibration, vol. 248, no. 1, pages 91-103, 2001.

9. M. Leahy, D. Mba, P. Cooper, A. Montgomery, D. Owen, Acoustic Emission technology for detection of shaft-to-seal rubbing on power generation turbines; a qualitative verification., INSIGHT, Vol. 48, no. 12, 754-755, Dec 2006. 
10. Al Shaikh Mubarak, M., Mba, D., Cooper, P., Opportunities offered by acoustic emission for seal and blade rub detection on large scale power generation turbines. 16th International congress on Condition monitoring and Diagnostic engineering management (COMADEM'2003) Vaxjo, Sweden, August $27^{\text {th }}-29^{\text {th }}$ 2003, p 513, ISBN 91-7636-376-7.

11. Journal-bearing Databook, Journal-bearing data book / editor Tsuneo Someya; with contributions by T. Someya, J. Mitsui, J. Esaki... [et. al.]. Berlin: Springer-Verlag, 1989. ISBN: 978-3540170747. Springer-Verlag Berlin and Heidelberg GmbH \& Co. K (October 1989).

12. Balerston, H. L., The detection of incipient failure in bearings, Materials Evaluation, Vol 27, 121-128, 1969.

13. Rogers, L. M., The application of vibration analysis and acoustic emission source location to on-line condition monitoring of anti-friction bearings. Tribology International, 1979; 51-59.

14. Yoshioka T, Fujiwara T. New acoustic emission source locating system for the study of rolling contact fatigue, Wear, 81(1), 183-186.

15. Holroyd, T.J. and Randall, N., (1993), Use of Acoustic Emission for Machine Condition Monitoring, British Journal of Non-Destructive Testing, 1993, $35(2), 75-78$.

16. Saad Al-Dossary, R.I. Raja Hamzah, D. Mba, Observations of changes in acoustic emission waveform for varying seeded defect sizes in a rolling element bearing, Journal of Applied Acoustics, Vol. 70, No. 1, Jan 2009, p 58 - 81, ISSN 0003-682X

17. R.I. Raja Hamzah, D. Mba, , THE INFLUENCE OF OPERATING CONDITION ON ACOUSTIC EMISSION (AE) GENERATION DURING MESHING OF HELICAL AND SPUR GEAR, Tribology International, Vol. 42, Iss. 1, 3-14, 2009

18. M. Elforjani, D. Mba, Natural mechanical degradation measurements in slow speed bearings, Engineering Failure Analysis, Volume 16, Issue 1, January 2009, Pages 521-532. 
19. Babak Eftekharnejad, D. Mba, ACOUSTIC EMISSION SIGNALS ASSOCIATED WITH DAMAGED HELICAL GEARS, INSIGHT, Volume: 50, Issue: 8, 450-453, Aug 2008.

20. R.I. Raja Hamzah, D.Mba, ACOUSTIC EMISSION AND SPECIFIC FILM THICKNESS $(\lambda)$ FOR SPUR GEARS, INSIGHT, Vol. 50, No. 11, 642-643, Nov 2008

21. J. Couturier, D. Mba, operational bearing parameters and acoustic emission generation, Journal of Vibration and Acoustics, ASME, Vol 130, 024502, April 2008.

22. M. Elforjani, D. Mba, Monitoring the onset and propagation of natural degradation process in a slow speed rolling element bearing with Acoustic Emissions, ASME, Journal of Vibration and Acoustics, 130, 041013 (2008).

23. J.Z. Sikorska and D. Mba' Truth, Lies acoustic emission and process machines, Journal of Mechanical Process Engineering, Part E, IMechE, Volume 222, Number 1, 1-19, 2008.

24. Holroyd, T. Condition monitoring of very slowly rotating machinery using AE techniques. 14th International congress on Condition monitoring and Diagnostic engineering management (COMADEM'2001), Manchester, UK, 46 September 2001, 29, ISBN 0080440363.

25. Bagnoli, S., Capitani, R. and Citti, P. Comparison of accelerometer and acoustic emission signals as diagnostic tools in assessing bearing. Proceedings of 2nd International Conference on Condition Monitoring, London, UK, May 1988, 117-125.

26. Tandon, N. and Nakra, B.C, Defect Detection of Rolling Element Bearings by Acoustic Emission Method, Journal of Acoustic Emission, 1990; 9(1) 25-28.

27. Choundhury, A. and Tandon, N., Application of acoustic emission technique for the detection of defects in rolling element bearings, Tribology International, 2000; 33, 39-45.

28. Tan, C.C. Application of acoustic emission to the detection of bearing failures. The Institution of Engineers Australia, Tribology conference, Brisbane, 3-5 December 1990, 110-114.

29. Morhain, A, Mba, D, Bearing defect diagnosis and acoustic emission, Journal of Engineering Tribology, I Mech E, Vol 217, No. 4, Part J, p 257-272, 2003. ISSN 1350-6501. 


\section{APPENDIX A}

Table A1 AE r.m.s and minimum film thickness values

\begin{tabular}{|c|c|c|c|c|c|c|c|c|c|c|c|c|}
\hline $\begin{array}{c}\text { Film Thicknesss } \\
\boldsymbol{\mu m}\end{array}$ & $\mathbf{8 0 0} \mathbf{N}$ & $\mathbf{\%}$ & $\mathbf{7 0 0} \mathbf{N}$ & $\mathbf{\%}$ & $\mathbf{6 0 0} \mathbf{N}$ & $\mathbf{\%}$ & $\mathbf{5 0 0} \mathbf{N}$ & $\mathbf{\%}$ & $\mathbf{4 0 0} \mathbf{N}$ & $\mathbf{\%}$ & $\mathbf{3 0 0} \mathbf{N}$ & $\mathbf{\%}$ \\
\hline $\mathbf{4 0 0 0} \mathbf{~ r p m}$ & 38.81 & -0.63 & 38.95 & -0.37 & 39.05 & -0.20 & 39.17 & -0.10 & 39.31 & -0.01 & 39.46 & 0.03 \\
\hline $\mathbf{3 0 0 0} \mathbf{~ r p m}$ & 38.57 & 0.90 & 38.81 & 0.78 & 38.97 & 0.59 & 39.13 & 0.48 & 39.30 & 0.41 & 39.47 & 0.28 \\
\hline $\mathbf{2 0 0 0} \mathbf{~ r p m}$ & 38.91 & 0.50 & 39.11 & 0.35 & 39.21 & 0.32 & 39.32 & 0.27 & 39.46 & 0.21 & 39.58 & 0.18 \\
\hline $\mathbf{1 0 0 0} \mathbf{~ r p m}$ & 39.11 & -0.19 & 39.25 & -0.08 & 39.33 & -0.06 & 39.42 & -0.05 & 39.55 & -0.07 & 39.65 & 0.03 \\
\hline $\mathbf{5 0 0} \mathbf{~ r p m}$ & 39.03 & - & 39.22 & - & 39.31 & - & 39.40 & - & 39.52 & - & 39.67 & - \\
\hline
\end{tabular}

Table A2 Changes in AE r.m.s levels for varying speed and load conditions

\begin{tabular}{|c|c|c|c|c|c|c|c|c|c|c|c|c|}
\hline AE r.m.s & $\mathbf{8 0 0} \mathbf{N}$ & $\mathbf{\%}$ & $\mathbf{7 0 0} \mathbf{N}$ & $\mathbf{\%}$ & $\mathbf{6 0 0} \mathbf{N}$ & $\mathbf{\%}$ & $\mathbf{5 0 0} \mathbf{N}$ & $\mathbf{\%}$ & $\mathbf{4 0 0} \mathbf{N}$ & $\mathbf{\%}$ & $\mathbf{3 0 0} \mathbf{N}$ & $\mathbf{\%}$ \\
\hline $\mathbf{4 0 0 0} \mathbf{~ r p m}$ & 0.0009 & 92.89 & 0.0006 & 165.32 & 0.0007 & 147.48 & 0.0006 & 178.42 & 0.0006 & 176.73 & 0.0005 & 192.01 \\
\hline $\mathbf{3 0 0 0} \mathbf{~ r p m}$ & 0.0018 & 315.48 & 0.0017 & 324.53 & 0.0016 & 341.08 & 0.0017 & 311.93 & 0.0016 & 308.24 & 0.0016 & 318.60 \\
\hline $\mathbf{2 0 0 0} \mathbf{~ r p m}$ & 0.0074 & 192.32 & 0.0070 & 204.87 & 0.0073 & 185.06 & 0.0069 & 200.75 & 0.0067 & 194.85 & 0.0065 & 219.97 \\
\hline $\mathbf{1 0 0 0} \mathbf{~ r p m}$ & 0.0216 & 79.20 & 0.0215 & 76.94 & 0.0207 & 80.49 & 0.0209 & 81.97 & 0.0198 & 96.09 & 0.0209 & 80.20 \\
\hline $\mathbf{5 0 0} \mathbf{~ r p m}$ & 0.0387 & - & 0.0380 & - & 0.0374 & - & 0.0379 & - & 0.0389 & - & 0.0377 & - \\
\hline
\end{tabular}

Table A3 Relative percentage changes in AE r.m.s and total power loss

\begin{tabular}{|c|c|c|c|c|}
\hline \% & Total KW & Total KW \% & AE r.ms & AE r.ms \% \\
\hline $\mathbf{5 0 0 ~ r p m ~}$ & 0.159 & - & 0.001 & - \\
\hline $\mathbf{1 0 0 0} \mathbf{~ r p m}$ & 0.298 & 87 & 0.002 & 152 \\
\hline $\mathbf{2 0 0 0} \mathbf{~ r p m}$ & 0.795 & 166 & 0.007 & 319 \\
\hline $\mathbf{3 0 0 0} \mathbf{~ r p m}$ & 1.451 & 82 & 0.021 & 199 \\
\hline $\mathbf{4 0 0 0} \mathbf{~ r p m}$ & 1.861 & 28 & 0.038 & 82 \\
\hline
\end{tabular}

